\title{
Remodelling compartment in root cementum
}

\author{
J.F. Brochado Martins ${ }^{1}$, C.F.D. Rodrigues², P. Diogo ${ }^{3}$, S. Paulo ${ }^{3}$, P.J. Palma ${ }^{3}$, \\ F.F. do Vale ${ }^{4}$ \\ ${ }^{1}$ Hard Tissues Laboratory, Faculty of Medicine, University of Coimbra, Portugal \\ 2Internal Medicine Department II, Hospital Infante D. Pedro, Centro Hospitalar do Baixo Vouga, Aveiro, Portugal \\ 3Institute of Endodontics, Faculty of Medicine, University of Coimbra, Portugal \\ ${ }^{4}$ Institute of Orthodontics, Faculty of Medicine, University of Coimbra, Portugal
}

[Received: 26 August 2020; Accepted: 23 October 2020; Early publication date: 3 November 2020]

\begin{abstract}
Background: Bone remodelling represents the most remarkable bone response to mechanical stress and mineral homeostasis. It is the consequence of complex highly orchestrated and tightly regulated cellular processes taking place in a specialised entity - the bone remodelling compartment (BRC).

Materials and methods: Cementum is an understudied tissue that requires more research to understand its biology, pathology, and potential for regeneration. Although analogue to bone in structure and composition distinct structural and functional differences were ascribed to each of these mineralised tissues. The precise role of cementocytes in cementum turnover is unclear but they may work the same way as osteocytes in bone remodelling, regulating the full process.

Results: Although cementum is not liable to regular physiological remodelling as bone is, pathological cases triggered by orthodontic forces or large periapical periodontitis, those lesions can acutely induce cementum remodelling. Nevertheless, the cellular mechanisms behind this particular remodelling process are yet to be identified, as its eventual involvement of specialised anatomic structures as the $B R C$.

Conclusions: Hypothesizing that similar cellular mechanisms underlie bone and cementum remodelling, the present work shows, for the first time, the histological evidence of a specialized remodelling compartment in dental hard tissues. (Folia Morphol 2021; 80, 4: 972-979)
\end{abstract}

Key words: bone remodelling compartment, bone, cementum, cementocytes, root resorption

\section{INTRODUCTION}

The importance of a specified structure overlying the bone-remodelling unit named bone-remodelling compartment (BRC) has been underlined by several authors $[1,7,11,15,25]$. This structure unit is formed by a canopy of bone lining cells, under which the remodelling process takes place isolated from the remaining intact tissues $[4,7,11,15,25]$. The spe- cific and non-random localisation of blood capillaries and sinusoids close to the BRC ensures a fast access and targeted delivery of systemic regulators to the remodelling compartment, enabling guidance of osteoclasts and osteoblasts progenitors to critical points on the bone surface $[1,7,18]$. By secreting critical factors and expressing specific receptors, canopy cells along with osteocytes are the main orchestrators of

Address for correspondence: J.F. Brochado Martins, DDS, MSc, Hard Tissues Laboratory, Faculty of Medicine, University of Coimbra, Avenida Bissaya Barreto, Blocos de Celas - CHUC 3000-075 Coimbra, Portugal, fax: +351239402910, e-mail: jfbrochado@gmail.com

This article is available in open access under Creative Common Attribution-Non-Commercial-No Derivatives 4.0 International (CC BY-NC-ND 4.0) license, allowing to download articles and share them with others as long as they credit the authors and the publisher, but without permission to change them in any way or use them commercially. 
the overall remodelling process, being the canopy an important reservoir of osteoblast progenitors during remodelling [14].

Bone resorption and formation is synchronized by direct cell contact between osteoblasts and osteoclasts and a variety of secreted factors [28]. It has also been established that the tight equilibrium between these two cellular populations is fundamentally maintained by a triad of elements composed by osteoprotegerin (OPG), the receptor activator of NF- $\kappa \beta$ (RANK) and the RANK ligand (RANKL) $[3,18$, $20,31]$. However, osteocytes prevailed as the main orchestrators of the overall remodelling process, as they are the only cells with the lacuno-canalicular network, endowed with the capability to detect load changes, and consequently activate cellular signalling cascades aimed at either bone reabsorption or remodelling $[25$, 32]. In fact, several studies had demonstrated that osteocytes are the major source of RANKL in the bone tissue, and not the osteoblasts $[2,22,29]$.

Osteocytes act as mechanosensing cells and initiate the remodelling process predominantly when microfractures and loading are involved $[5,26,35]$. In these situations, osteocytes' physiology is profoundly altered and apoptosis is triggered [13, 35, 37]. As a consequence, osteoclastogenesis and bone reabsorption prevail, thus driving deep changes in bone tissue architecture $[8,17]$. It is reasonable to conclude that the osteocyte acts as the leading mechanosensor in bone, which has also been recently confirmed by targeted ablation of osteocytes in a mouse model [32].

Cementum prevails as the least-known mineralised tissue and is often referred to as a bone-like tissue. It is, however, avascular and non-innervated, it lacks marrow and the typical lamellar organization of the bone, and it does not undergo dynamic remodelling or increased thickness throughout life [38]. On contrary, both cementocytes and osteocytes are sensitive to mechanical features, mainly pressure and trauma $[9,23]$. Finally, cementocytes express RANKL and sclerostin, thus underlying their particular importance on triggering cementum resorption, remodelling and repair, which eventually occurs in a similar way as bone remodelling $[10,19,34]$. Although cementum is not exposed to regular physiologic remodelling, recent evidence showed that cementum resorption might be triggered under specific circumstances as, for example, orthodontic forces or large apical periodontitis lesions.
The purpose of this work was to evaluate the effect of a distraction protocol on bone remodelling and root surface of the anchoring teeth.

The results hereby presented describe the identification of a specialised remodelling structure, which we refer to as the cementum remodelling compartment (CRC). It is associated with cementum at the dental root surfaces, and this work provides a description on its light microscopic morphology and cellular phenotype in comparison to the BRC.

\section{MATERIALS AND METHODS}

\section{Animals}

Four skeletal mature conditioned male Beagle dogs, 1 year old and weighing 15 to $18 \mathrm{~kg}$, were selected for the study. Animals were kept in adequate standard structures, precisely identified and with the appropriate conditions of light and temperature. The water, administered ad libitum to the animals, was originated from the municipal supply network. Food was provided once daily, as commercial dry feed (Canine Adult Lamg \& Rice, Chicken Advanced Fitness, Hills ${ }^{\mathrm{TM}}$ ) with concentrations of contaminants analysed and monitored by the manufacturer. After surgical intervention and during latency and mandibular stretching phases, the dry feed was softened in warm water (ratio 1:3). From the consolidation period until euthanasia, the softened food was mixed with water in a ratio 1:1. All animal procedures were conducted according to the European Union Directive 2010/63/EU for animal experiments and reviewed and approved by DGAV (no 0420/000/000/2012) and the animal facility ethics committee.

\section{Anaesthesia protocol}

Dogs were anesthetised by intravenous administration of $0.2 \mathrm{mg} / \mathrm{kg}$ diazepam (Diazepam Labesfal, Portugal) and $2 \mathrm{mg} / \mathrm{kg}$ propofol (Propofol Lipuro 2\%, Braun Medical, Portugal), and maintained alive with inhalation of oxygen and 1-2\% isoflurane (Isoflo, Esteve Farma, Portugal).

\section{Experimental group}

Three animals underwent mandibular distraction following bilateral midbody osteotomy (between the third and fourth premolar), to preserve the integrity of the mandibular nerve and lingual periosteum. After ensuring bone mobility, tooth distractor was placed in each hemimandible, using the third and the fourth premolars as anchorage teeth for the distraction ap- 
paratus. The 6 hemimandibles were subjected to a repeated daily activation of $1 \mathrm{~mm}$, with moderate to severe pressure applied to the anchorage teeth for 10 days ( $10 \mathrm{~mm}$ in total), followed by a consolidation period of 12 weeks.

\section{Control group}

Two hemimandibles underwent no treatment. The animal was kept under the same conditions as its experimental counterparts, for the same period of time.

\section{Euthanasia protocol}

Animals were euthanized by anaesthetic overdose (pentobarbital $100 \mathrm{mg} / \mathrm{kg}$ intravenously, Pentotal, Abbot, Portugal), followed by bilateral perfusion with $10 \%$ phosphate buffered formalin (PRS Panreac, Spain).

\section{Histological analysis}

Histological processing was carried out at the Hard Tissues Laboratory of the Faculty of Medicine of the University of Coimbra. Half of the samples were prepared for histological evaluation in non-decalcified material and the other half for decalcified material. Mandibular blocks were dissected. Half of the samples from the anchorage teeth were processed and embedded in methylmethacrylate, sectioned and ground to a thickness of $20 \mu \mathrm{m}$ on Exact Cutting-Grinding System (Exakt ${ }^{\circledast}$ Apparatebau, GmbH \& CO, Norderstedt, Hamburg, Germany). Mandibular blocks were dissected, post-fixed with $10 \%$ phosphate buffered formalin and subsequently decalcified with Morse's solution for 8 weeks. The specimens were then trimmed and embedded in paraffin wax, and 30 serially sections with $6 \mu \mathrm{m}$ each were subsequently prepared. Toluidine blue, haematoxylin-eosin and Masson trichromic were used to stain the specimens for bone tissue, periodontal tissue and the radicular structure. Histological assessment was performed under a light microscope (Nikon ${ }^{\circledR}$ SMZ 1500, Tokyo, Japan), attached to digital cameras (Optronics ${ }^{\circledast}$ DEI 750D CE, Goleta, California, USA and Nikon ${ }^{\circledast}$ Digital Camera DXM-1200 C, Tokyo, Japan) connected to a computer (Intel ${ }^{\circledast}$ Pentium $^{\text {TM }}$ III and Intel ${ }^{\circledR}$ Core $^{T M} 2$ Duo Core ${ }^{T M}$ ) with an image software analysis programme (Nikon ${ }^{\circledR}$ ACT-1C, Tokyo, Japan) for the evaluation of the bone tissue and root surfaces. One observer blinded to all group's allocation examined all specimens. The images were prepared and edited with Adobe Illustrator CC 2017, Adobe Systems.

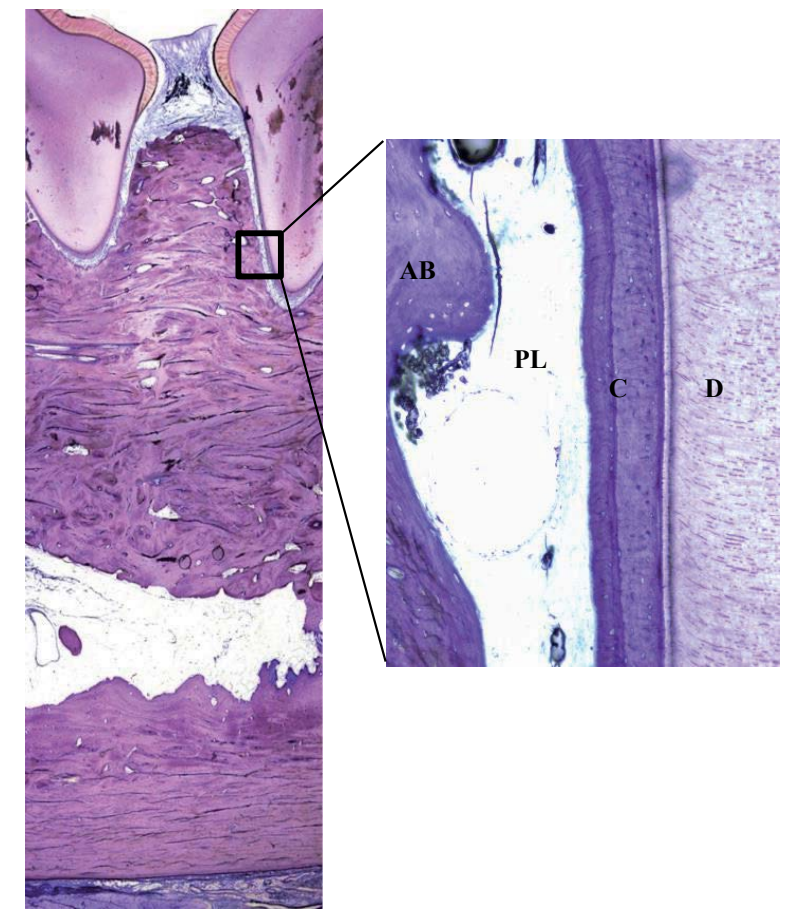

Figure 1. Histologic section of a hemimandible attained from the control group dog depicting normal bone tissue architecture (toluidine blue, $\times 7.5$ in the original). Higher magnification of the periodontal apparatus $(\times 100)$ showing the alveolar bone $(A B)$, the space of the periodontal ligament (PL), cementum (C) and dentin (D).

\section{RESULTS}

Following the experimental protocol, dogs were euthanized and the mandibles collected and processed for histological analysis. Not surprisingly, hemimandibles from the control group displayed normal radicular architecture and bone histology (Fig. 1).

In the experimental group, however, although the distraction protocol did not induce alterations in either the routine or the alimentary habits of the animals, bone remodelling was observed inside the BRC in both groups (Figs. 2, 3). The first evidence of bone reabsorption was indicated by the detachment of the bone lining cells from the bone surface, and the invasion of clastic cells to attach to the denuded bone matrix surface (Fig. 2.1). Reversal cells were subsequently recruited to the BRC and repopulated the bone surface, and osteoblasts were embedded by mineralized bone matrix (Fig. 2.2, black arrow). Figure 2.3 displays what is believed to be a pericyte (red arrow) lying just above the canopy. During bone formation phase, osteoblasts (OsB) populated the bone surface, layering osteoid, while flattened cells with thin and flat nucleus bordering the marrow side and forming the canopy of the BRC (Fig. 3). 

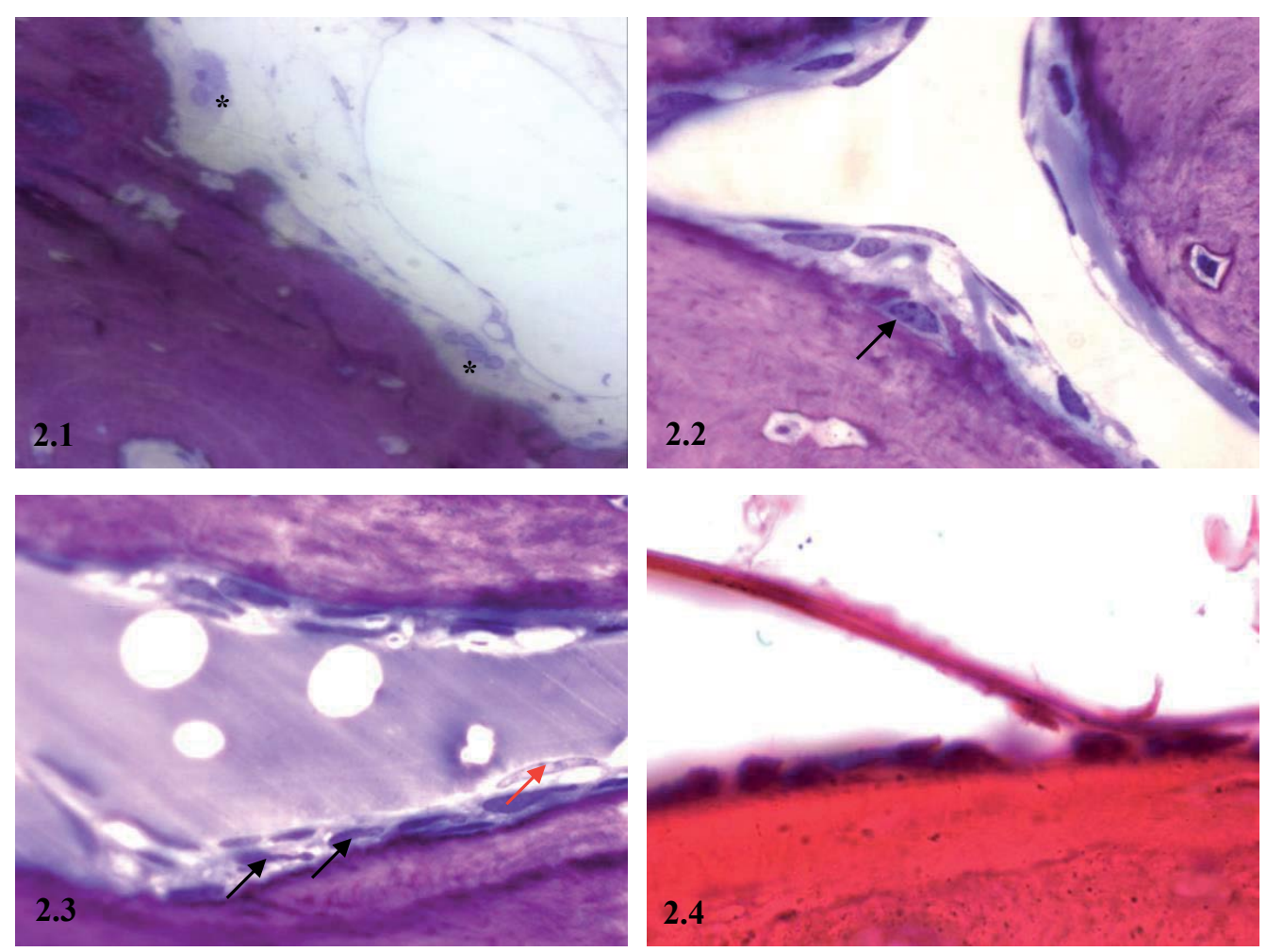

Figure 2. The bone remodelling compartment; 2.1. Microphotography of a bone remodelling compartment, in resorption phase, observed in the compact bone tissue. Howship lacuna and several osteoclasts $\left(^{*}\right)$ are observed on the bone surface, in close proximity to a blood vessel (toluidine blue, $\times 400$ in the original); 2.2. Reversal phase. It is also observed of a blood vessel in close proximity to bone remodelling compartment (BRC) as well as an osteoblast being embedded by the extracellular matrix (black arrow) (toluidine blue, $\times 400$ in the original); 2.3. Reversal phase of bone remodelling compartment, in compact bone tissue containing in its interior a great density of elongated cells, the reversal cells (black arrows). Note the presence a pericyte (red arrow) (toluidine blue, $\times 400$ in the original); 2.4. Morphological appearance of the initial formation of the BRC canopy in a trabecula of alveolar woven bone (haematoxylin-eosin, $\times 1000$ in the original).

Remodelling was also observed in discreet zones along the dental root (Fig. 4). Surprisingly, however, it also implicated the formation of a special remodelling compartment, delineated by a canopy of flat cells in close proximity to the blood vessels (Fig. 4.1). In fact, a Howship lacuna reaching dentine was observed, along with a layer of flattened cells (Fig. 4.1, black arrow) that formed the equivalent to the canopy. Even though no clastic cells were identified, the ones close to the cementum and dentin surfaces displayed characteristics of reversal cells, and they also repopulated the resorption area during the formation phase. Because it was difficult to distinguish the canopy from the endothelial cells, a complete remodelling compartment could not be perfectly delineated. However, a singular cell-rich space between the mineralised tissues and a blood vessel was evident, resembling the remodelling progression in the characteristic cutting cones of the compact bone tissue (Fig. 4.2). Moreover, by morphologic comparison to the bone tissue, the cell population adjacent to the dentin and cementum surface most probably represented the beginning of the reversal phase (Fig. 4.2). Finally, the tissue apposition phase was also recognised in the cement remodelling process by the identification of a remodelling compartment next to a newly formed cementum area, covered by cementoid tissue and cementoblasts (Figs. 4.3, 4.4). Figure 4.3 illustrates in detail canopy cells and a layer of cuboid cementoblasts, morphologically similar to osteoblasts, adjacently placed to a region of non-mineralised cement. It also identifies a band of mineralized matrix of cementum repairing an area of resorbed dentin matrix, as well as a region of dentin portraying its typical tubular structure.

\section{DISCUSSION}

The present work provides evidence of organized cementum remodelling taking place inside specific structures along the dental root of distracted tooth, similarly to bone remodelling inside BRCs. These structures, named CRCs, are formed to enclose local factors and potentiate the remodelling process. They are also 

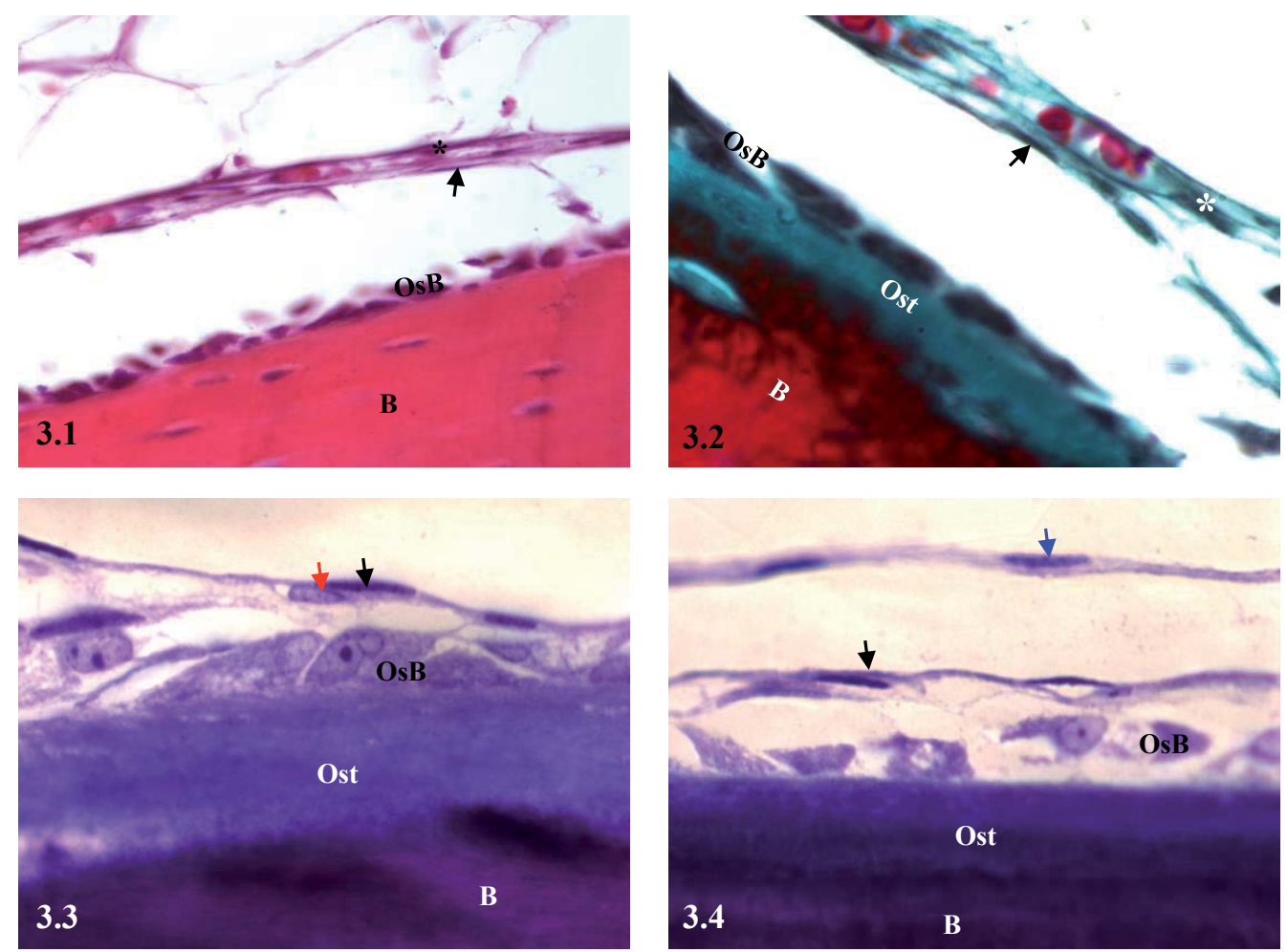

Figure 3. Osteo-angiogenic platform; 3.1. Histologic section of the capillary network located next to the canopy of a bone remodelling compartment (BRC), running along in a parallel direction in almost all its extension. Close proximity between endothelial cells $\left({ }^{*}\right)$ and lining cells (black arrow); B - bone; OsB - osteoblasts (haematoxylin-eosin, $\times 200$ in the original); 3.2. Histological section of a capillary following a parallel path to the canopy of a BRC, in formative phase. Close proximity between endothelial cells ( ${ }^{*}$ ) and lining cells (black arrow); B bone; OsB — osteoblasts; Ost — osteoid; black arrow — canopy (Masson's trichromic, $\times 400$ in the original); 3.3. Microphotograph of a blood capillary following in close proximity the remodelling compartment. Cell intimately adjacent to the endothelial wall (black arrow) is seen as a pericyte (red arrow) (toluidine blue, $\times 1000$ in the original); 3.4. Histological aspect of the constitution of a BRC in bone formation phase, located on the surface of a trabecula. Osteoblasts $(\mathrm{OsB})$, coating cells that form the canopy (black arrow), the proximity of a blood vessel (blue arrow) that runs parallel path to the canopy; B - bone; 0sB - osteoblasts; 0 st - osteoid (toluidine blue, $\times 1000$ in the original).

delineated by a flattened canopy of cells, and always localise in close proximity to blood vessels, thus allowing the trade of cells and/or systemic factors from the bloodstream.

Cementum is a highly responsive mineralized tissue, and its biological activity is of extreme importance to maintain the integrity of the root, namely its adequate position. It shares morphological, functional and biochemical similarities with the bone tissue; however, cementum is avascular and consequently depicts higher levels of hypoxia [34, 39]. There are two main types of cementum fibres, acellular extrinsic fibres (AEFCs) and cellular intrinsic cementum fibres (CIFCs). According to Schroeder [30], AEFCs are mostly involved in tooth support, and thus are the ones recruited following tooth distraction; while CIFCs, on the other hand, appear to be more associated with tooth adaptation, i.e. the reshaping of the root surface during tooth' movement. CIFCs are also recruited as reparative cementum to fulfil the resorbed root surfaces [30]. The results attained in the present work come to support others in the literature postulating that given the similarities between the bone and cementum, it is reasonable to hypothesise that cementocytes may play a central regulatory role in the homeostasis and remodelling of cementum, not only following extrinsic stimulation, but also during the normal orthodontic movement and endodontic infections [12, 27, 30, 38, 39].

Cementum remodelling, as the bone, also depends upon a mechanic stimulus to be transmitted to the mineralised tissue matrix, and the consequent triggering of the reabsorption-formation cascade. In agreement, the application of a severe pressure to the anchored teeth of the animals in this study, triggered a radicular cementum remodelling, along with alveolar bone remodelling and redistribution of the principal fibres, thus driving dental repositioning. In fact, even though cementum is more resistance to resorption than bone, when orthodontic forces are 

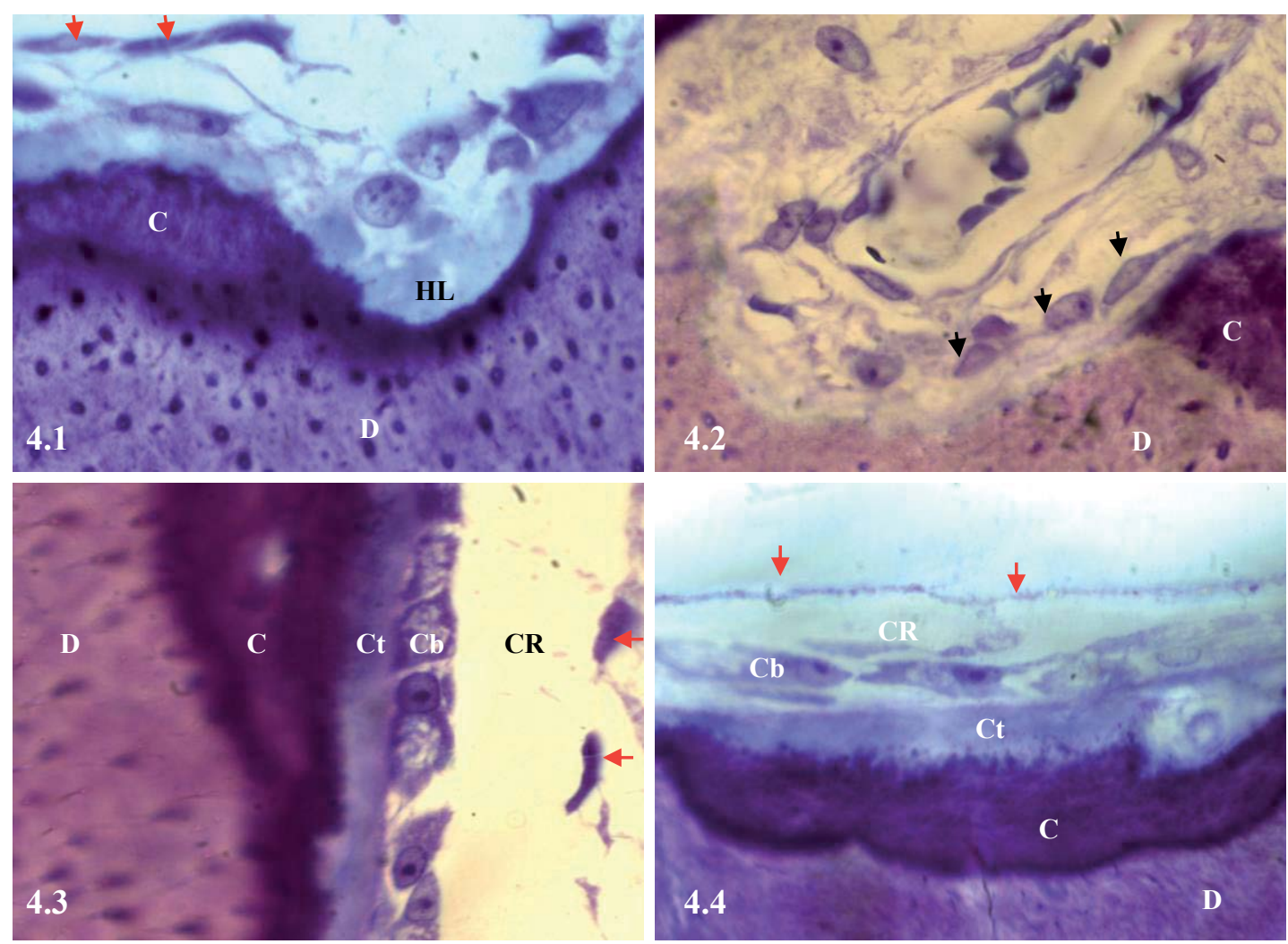

Figure 4. Dental hard tissue remodelling compartment; 4.1. Resorption phase observed in the cement reaching the dentin, showing Howship lacunae $(\mathrm{HL}$ ) even without the presence of odontoclasts. It is possible to observe some canopy cells (red arrows); $\mathrm{D}-$ dentin; $\mathrm{C}-$ cement (toluidine blue, $\times 400$ in the original); 4.2. Dentine resorption area aspect (D) with the reversal cells (black arrows) close to resorption areas. It is obvious the resemblance to a cutting cone observed in compact bone tissue including the presence of a central blood vessel (toluidine blue, $\times 1000$ in the original); 4.3. Appearance of a remodelling compartment in the formation phase located in the cementum adjacent to the dentin showing a cementum area $(\mathrm{C})$ covered by cementoid $(\mathrm{Ct})$ and cementoblasts $(\mathrm{Cb})$, remodelling compartment (CR) and the canopy (red arrows) (toluidine blue, $\times 400$ in the original); 4.4. Analogous image to the previous, showing a dentine area (D), mineralised cementum (C), cementoid (Ct), a cementoblasts layer (Cb), a space corresponding to the remodelling compartment (CR) and the canopy (red arrows) (toluidine blue, $\times 1000$ in the original).

applied, they not only disrupt cementum's structure, but proceed invading the root dentin [12]. Studies in orthodontic patients to whom extrinsic forces were applied, showed that the application of an external pressure to the dental root activated cementoblasts, and consequently drove the removal of the cementum from the root surface, followed by a cementoblast-mediated restoration [16, 21, 33, 38].

Root repair is constant during orthodontic tooth movement, and permanent total root loss only occurs if the tooth structure is not fully repaired [6]. Using a mice endodontic infection model, Rossi et al. [27] proved that in healthier mature teeth, cementocytes and osteocytes did not express RANKL. In response to infection, however, RANKL was strongly expressed by cementocytes and its expression increased along the lesion and time progression, an effect that was not observed in osteocytes [27]. The detection of a CRC emphasizes the fact that hard tissues remodelling is a demanding and controlled process that might not occur with external interferences; thus, a remodelling compartment is created to allow local regulation of the process. Simultaneously, the canopy may act as a diffusion barrier for cytokines, growth factors and chemoattractants, thus allowing systemic factors to act over the cells inside the remodelling compartment $[20,24]$. Moreover, its presence seems to have a crucial impact on the overall remodelling cycle success, as highlighted by several studies on diverse pathologic situations where the absence of BRC canopies beyond eroded surfaces was correlated with a greater amount of arrested reversal surfaces and a reduced amount of bone formation, thus reflecting both disrupted and arrested remodelling cycles [36]. Besides, the absence of BRC canopies above formative surfaces leads to a shift in the osteoblastic phenotype, which 
causes an arrest or even the non-progression of the formative phase. Altogether, these facts suggest that BRC canopies had a critical role for longevity, function and the control and coordination of the underlying cells activity [36], and the same may be envisioned for the CRC. In agreement, remodelling areas with fragmented canopies were also observed in the animals under study, and were also associated to the interruption or arrest of the formative or inversion phases, driving cementolytic lesions that the authors hypothesise that may also occur in humans.

\section{Limitations of this study}

Limitations of this study include the fact that it is merely an observational study meant to report the existence and identification of the CRC. To determine the cellular ultrastructure as well as the nature and function of each type of cells involved, immunohistochemistry and electron microscopy would be needed. Additionally, more studies are needed to clarify the interactions of the multiple signal transduction pathways. It is also likely that the future holds the discovery of novel molecules that will lead to further insights into the mechanisms responsible for cementum formation and resorption.

\section{CONCLUSIONS}

This is the first study to identify and histologically describe a histologic remodelling structure in dental mineralised tissues, which the authors named CRC. The existence of such a remodelling compartment in cementum, and the fact that it shares so many defining characteristics with the BRC, may hide the existence of a common underlying cellular mechanism that regulates remodelling of the hard tissues. Understanding physiology underlying the dynamics of cementum modelling and remodelling will be essential for the comprehension of its kinetics in orthodontics and trauma.

\section{Acknowledgements}

Hard Tissue Histology Laboratory, Faculty of Medicine, University of Coimbra for assistance with the histological analysis (Mrs. Cláudia Brites).

\section{Conflict of interest: None declared}

\section{REFERENCES}

1. Andersen TL, Sondergaard TE, Skorzynska KE, et al. A physical mechanism for coupling bone resorption and formation in adult human bone. Am J Pathol. 2009; 174(1): 239-247, doi: 10.2353/ajpath.2009.080627, indexed in Pubmed: 19095960.
2. Bellido T. Osteocyte-driven bone remodeling. Calcif Tissue Int. 2014; 94(1): 25-34, doi: 10.1007/s00223-013-9774-y, indexed in Pubmed: 24002178.

3. Boyce BF, Xing L. Functions of RANKL/RANK/OPG in bone modeling and remodeling. Arch Biochem Biophys. 2008; 473(2): 139-146, doi: 10.1016/j.abb.2008.03.018, indexed in Pubmed: 18395508.

4. Feng $\mathrm{Xu}$, Teitelbaum SL. Osteoclasts: New Insights. Bone Res. 2013; 1(1): 11-26, doi: 10.4248/BR201301003, indexed in Pubmed: 26273491.

5. Goulet GC, Cooper DML, Coombe D, et al. Influence of cortical canal architecture on lacunocanalicular pore pressure and fluid flow. Comput Methods Biomech Biomed Engin. 2008; 11(4): 379-387, doi: 10.1080/10255840701814105, indexed in Pubmed: 18568832.

6. Hartsfield JK. Pathways in external apical root resorption associated with orthodontia. Orthod Craniofac Res. 2009; 12(3): 236-242, doi: 10.1111/j.1601-6343.2009.01458.x, indexed in Pubmed: 19627526.

7. Hauge EM, Qvesel D, Eriksen EF, et al. Cancellous bone remodeling occurs in specialized compartments lined by cells expressing osteoblastic markers. J Bone Miner Res. 2001; 16(9): 1575-1582, doi: 10.1359/jbmr.2001.16.9.1575, indexed in Pubmed: 11547826.

8. Henriksen $K$, Neutzsky-Wulff AV, Bonewald LF, et al. Local communication on and within bone controls bone remodeling. Bone. 2009; 44(6): 1026-1033, doi: 10.1016/j. bone.2009.03.671, indexed in Pubmed: 19345750.

9. Huang L, Meng Y, Ren A, et al. Response of cementoblast-like cells to mechanical tensile or compressive stress at physiological levels in vitro. Mol Biol Rep. 2009; 36(7): 1741-1748, doi: 10.1007/s11033-008-9376-3, indexed in Pubmed: 18850302.

10. Jäger A, Götz W, Lossdörfer S, et al. Localization of SOST/ sclerostin in cementocytes in vivo and in mineralizing periodontal ligament cells in vitro. J Periodontal Res. 2010; 45(2): 246-254, doi: 10.1111/j.1600-0765.2009.01227.x, indexed in Pubmed: 19778325.

11. Jensen PR, Andersen TL, Søe K, et al. Premature loss of bone remodeling compartment canopies is associated with deficient bone formation: a study of healthy individuals and patients with Cushing's syndrome. J Bone Miner Res. 2012; 27(4): 770-780, doi: 10.1002/jbmr.1490, indexed in Pubmed: 22162180.

12. Krishnan V, Davidovitch Z. Cellular, molecular, and tissue-level reactions to orthodontic force. Am J Orthod Dentofacial Orthop. 2006; 129(4): 469.e1-469.32, doi: 10.1016/j. ajodo.2005.10.007, indexed in Pubmed: 16627171.

13. Krishnan V, Davidovitch Z. On a path to unfolding the biological mechanisms of orthodontic tooth movement. J Dent Res. 2009; 88(7): 597-608, doi: 10.1177/0022034509338914, indexed in Pubmed: 19641146.

14. Kristensen HB, Andersen TL, Marcussen N, et al. Osteoblast recruitment routes in human cancellous bone remodeling. Am J Pathol. 2014; 184(3): 778-789, doi: 10.1016/j.ajpath.2013.11.022, indexed in Pubmed: 24412092.

15. Kristensen HB, Andersen TL, Marcussen N, et al. Increased presence of capillaries next to remodeling sites in adult human cancellous bone. J Bone Miner Res. 2013; 28(3): 574-585, doi: 10.1002/jbmr.1760, indexed in Pubmed: 22991221.

16. Kumasako-Haga T, Konoo T, Yamaguchi K, et al. Effect of 8-hour intermittent orthodontic force on osteoclasts 
and root resorption. Am J Orthod Dentofacial Orthop. 2009; 135(3): 278.e1-8; discussion 278, doi: 10.1016/j. ajodo.2008.11.007, indexed in Pubmed: 19268821.

17. Kurata $K$, Heino TJ, Higaki $H$, et al. Bone marrow cell differentiation induced by mechanically damaged osteocytes in 3D gel-embedded culture. J Bone Miner Res. 2006; 21(4): 616-625, doi: 10.1359/jbmr.060106, indexed in Pubmed: 16598382.

18. Lafage-Proust MH, Roche $B$, Langer $M$, et al. Assessment of bone vascularization and its role in bone remodeling. Bonekey Rep. 2015; 4: 662, doi: 10.1038/bonekey.2015.29, indexed in Pubmed: 25861447.

19. Lehnen SD, Götz W, Baxmann M, et al. Immunohistochemical evidence for sclerostin during cementogenesis in mice. Ann Anat. 2012; 194(5): 415-421, doi: 10.1016/j. aanat.2012.02.014, indexed in Pubmed: 22560000.

20. Martin T, Gooi JH, Sims NA. Molecular mechanisms in coupling of bone formation to resorption. Crit Rev Eukaryot Gene Expr. 2009; 19(1): 73-88, doi: 10.1615/critreveukargeneexpr.v19.i1.40, indexed in Pubmed: 19191758.

21. Mullally NN. Cementoblastic Response to High vs. Low Level of Mechanical Force in Vitro. [dissertation]. Marquette University. 2010. Paper 41.

22. Nakashima T, Hayashi M, Fukunaga $T$, et al. Evidence for osteocyte regulation of bone homeostasis through RANKL expression. Nat Med. 2011; 17(10): 1231-1234, doi: 10.1038/nm.2452, indexed in Pubmed: 21909105.

23. Nanci A, Ten Cate AR. Ten Cate's - Oral Histology - Development, Structure, and Function. Sixth Ed. Mosby, St. Louis 2013.

24. Owen R, Reilly GC. models of bone remodelling and associated disorders. Front Bioeng Biotechnol. 2018; 6: 134, doi: 10.3389/fbioe.2018.00134, indexed in Pubmed: 30364287.

25. Parfitt AM. The bone remodeling compartment: a circulatory function for bone lining cells. J Bone Miner Res. 2001; 16(9): 1583-1585, doi: 10.1359/jbmr.2001.16.9.1583, indexed in Pubmed: 11547827.

26. Proff $P$, Römer $P$. The molecular mechanism behind bone remodelling: a review. Clin Oral Investig. 2009; 13(4): 355-362, doi: 10.1007/s00784-009-0268-2, indexed in Pubmed: 19319579.

27. Rossi AD, Fukada SY, De Rossi M, et al. Cementocytes express receptor activator of the Nuclear factor kappa-B ligand in Response to endodontic infection in mice. J Endod. 2016; 42(8): 1251-1257, doi: 10.1016/j.joen.2016.05.009, indexed in Pubmed: 27342005.

28. Sanchez-Fernandez MA, Gallois A, Riedl T, et al. Osteoclasts control osteoblast chemotaxis via PDGF-BB/PDGF receptor beta signaling. PLoS One. 2008; 3(10): e3537, doi: 10.1371/ journal.pone.0003537, indexed in Pubmed: 18953417.

29. Sapir-Koren R, Livshits G. Osteocyte control of bone remodeling: is sclerostin a key molecular coordinator of the balanced bone resorption-formation cycles? Osteoporos Int. 2014; 25(12): 2685-2700, doi: 10.1007/s00198-0142808-0, indexed in Pubmed: 25030653.

30. Schroeder H. Biological problems of regenerative cementogenesis: synthesis and attachment of collagenous matrices on growing and established root surfaces. Int Rev Cytol. 1992: 1-59, doi: 10.1016/s0074-7696(08)62074-4.

31. Sims NA, Gooi JH. Bone remodeling: multiple cellular interactions required for coupling of bone formation and resorption. Semin Cell Dev Biol. 2008; 19(5): 444-451, doi: 10.1016/j.semcdb.2008.07.016, indexed in Pubmed: 18718546.

32. Tatsumi S, Ishii K, Amizuka N, et al. Targeted ablation of osteocytes induces osteoporosis with defective mechanotransduction. Cell Metab. 2007; 5(6): 464-475, doi: 10.1016/j. cmet.2007.05.001, indexed in Pubmed: 17550781.

33. Tyrovola JB, Spyropoulos MN, Makou M, et al. Root resorption and the OPG/RANKL/RANK system: a mini review. J Oral Sci. 2008; 50(4): 367-376, doi: 10.2334/ josnusd.50.367, indexed in Pubmed: 19106463.

34. van Bezooijen RL, Bronckers AL, Gortzak RA, et al. Sclerostin in mineralized matrices and van Buchem disease. J Dent Res. 2009; 88(6): 569-574, doi: 10.1177/0022034509338340, indexed in Pubmed: 19587164.

35. Verborgt O, Gibson GJ, Schaffler MB. Loss of osteocyte integrity in association with microdamage and bone remodeling after fatigue in vivo. J Bone Miner Res. 2000; 15(1): 60-67, doi: 10.1359/jbmr.2000.15.1.60, indexed in Pubmed: 10646115.

36. Wesseling-Perry K. The BRC canopy: an important player in bone remodeling. Am J Pathol. 2014; 184(4): 924-926, doi: 10.1016/j.ajpath.2014.01.004, indexed in Pubmed: 24561288

37. Xing L, Boyce BF. Regulation of apoptosis in osteoclasts and osteoblastic cells. Biochem Biophys Res Commun. 2005; 328(3): 709-720, doi: 10.1016/j.bbrc.2004.11.072, indexed in Pubmed: 15694405.

38. Yamamoto T, Hasegawa T, Yamamoto T, et al. Histology of human cementum: Its structure, function, and development. Jpn Dent Sci Rev. 2016; 52(3): 63-74, doi: 10.1016/j. jdsr.2016.04.002, indexed in Pubmed: 28408958.

39. Zhao N, Foster BL, Bonewald LF. The cementocyte: an osteocyte relative? J Dent Res. 2016; 95(7): 734-741, doi: 10.1177/0022034516641898, indexed in Pubmed: 27029548 . 